\title{
Hypertension control in integrated HIV and chronic disease clinics in Uganda in the SEARCH study
}

Dalsone Kwarisiima', Mucunguzi Atukunda', Asiphas Owaraganise', Gabriel Chamie², Tamara Clark², Jane Kabami', Vivek Jain², Dathan Byonanebye ${ }^{1}$, Florence Mwangwa' ${ }^{1}$, Laura B. Balzer ${ }^{3}$, Edwin Charlebois², Moses R. Kamya ${ }^{1,4}$, Maya Petersen ${ }^{5}$, Diane V. Havlir ${ }^{2}$ and Lillian B. Brown ${ }^{2 *}$ (D)

\begin{abstract}
Background: There is an increasing burden of hypertension (HTN) across sub-Saharan Africa where HIV prevalence is the highest in the world, but current care models are inadequate to address the dual epidemics. HIV treatment infrastructure could be leveraged for the care of other chronic diseases, including HTN. However, little data exist on the effectiveness of integrated HIV and chronic disease care delivery systems on blood pressure control over time.

Methods: Population screening for HIV and HTN, among other diseases, was conducted in ten communities in rural Uganda as part of the SEARCH study (NCT01864603). Individuals with either HIV, HTN, or both were referred to an integrated chronic disease clinic. Based on Uganda treatment guidelines, follow-up visits were scheduled every 4 weeks when blood pressure was uncontrolled, and either every 3 months, or in the case of drug stock-outs more frequently, when blood pressure was controlled. We describe demographic and clinical variables among all patients and used multilevel mixed-effects logistic regression to evaluate predictors of HTN control.

Results: Following population screening (2013-2014) of 34,704 adults age $\geq 18$ years, 4554 individuals with HTN alone or both HIV and HTN were referred to an integrated chronic disease clinic. Within 1 year 2038 participants with HTN linked to care and contributed 15,653 follow-up visits over 3 years. HTN was controlled at 15\% of baseline visits and at 46\% (95\% Cl: 44-48\%) of post-baseline follow-up visits. Scheduled visit interval more frequent than clinical indication among patients with controlled HTN was associated with lower HTN control at the subsequent visit (aOR $=0.89 ; 95 \% \mathrm{Cl}$ 0.79-0.99). Hypertension control at follow-up visits was higher among HIV-infected patients than uninfected patients to have controlled blood pressure at follow-up visits (48\% vs 46\%; aOR $1.28 ; 95 \% \mathrm{Cl} 0.95-1$. 71).

Conclusions: Improved HTN control was achieved in an integrated HIV and chronic care model. Similar to HIV care, visit frequency determined by drug supply chain rather than clinical indication is associated with worse HTN control.
\end{abstract}

Trial registration: The SEARCH Trial was prospectively registered with ClinicalTrials.gov: NCT01864603.

Keywords: Hypertension, HIV/AIDS, Sub-Saharan Africa, Integrated care

\footnotetext{
* Correspondence: Lillian.Brown@ucsf.edu

${ }^{2}$ University of California San Francisco, San Francisco, CA, USA

Full list of author information is available at the end of the article
}

(c) The Author(s). 2019 Open Access This article is distributed under the terms of the Creative Commons Attribution 4.0 International License (http://creativecommons.org/licenses/by/4.0/), which permits unrestricted use, distribution, and reproduction in any medium, provided you give appropriate credit to the original author(s) and the source, provide a link to the Creative Commons license, and indicate if changes were made. The Creative Commons Public Domain Dedication waiver (http://creativecommons.org/publicdomain/zero/1.0/) applies to the data made available in this article, unless otherwise stated. 


\section{Background}

There is an increasing non-communicable disease (NCD) burden globally, with an estimated one billion people living with hypertension and about 9.4 million related deaths annually [1]. Global trends are mirrored in sub-Saharan Africa (SSA) [2-4] where hypertension has become a major public health problem [5]. Population surveys of prevalence reveal a large burden of undiagnosed and untreated hypertension across SSA [6-8], and suggest that even among individuals in care, hypertension is successfully controlled in less than a quarter [7].

HIV is more prevalent in SSA than anywhere else in the world [9] and the region is facing a dual HIV-NCD epidemic. The expansion of life-saving antiretroviral therapy (ART) has decreased HIV related morbidity and mortality $[10,11]$, leading to an aging population living with HIV who are more susceptible to NCDs such as hypertension [12, 13]. As concern about the management of NCDs among people living with HIV (PLHIV) grows, the infrastructure that has been built for the provision of ART and other care services must be leveraged and adapted to respond to the growing burden of NCDs among both PLHIV and HIV-uninfected populations.

In this setting, lessons learned from the HIV chronic disease treatment model can be applied to the management of other chronic diseases such as hypertension. Integrated care systems are more convenient for patients, decrease stigma associated with healthcare, and could be more efficient for government and non-governmental funders. However, evidence-based care models for scaling up integrated HIV/NCD care are lacking [14]. In particular, little is known about the health systems factors that might influence HTN control when leveraging HIV chronic care systems to provide care for persons with hypertension, with or without co-occurring HIV infection. In the HIV chronic care model, systems factors such as clinic waiting times, inconvenient clinic hours, and unfriendly attitudes from staff, and frequency of schedule visits are associated with patient engagement in care and clinical outcomes [15]. In addition, drug stock outs for cardiovascular medications are frequent in SSA [16] and visit frequency, which is often determined by drug supply, is associated with clinical outcomes in the HIV chronic care model [17, 18].

In the Sustainable East Africa Research in Community Health (SEARCH) study (NCT01864603), population level screening of HIV and HTN was performed at community health campaigns, and individuals with either or both diseases were linked to integrated care at local health facilities $[19,20]$. The integrated care model addressed many of the known structural barriers to engagement in care through flexible clinic hours with decreased wait times, patient-centered care, and welcoming attitudes. In this study we set out to: 1) characterize the patient population and HTN control over time among of adult residents who linked to HTN care using an integrated chronic care delivery model that offered treatment for both HTN and HIV disease and 2) evaluate predictors of HTN control over time.

\section{Methods \\ Study setting}

We studied 10 rural Ugandan communities participating in the intervention arm of the SEARCH Study. Communities selected for the SEARCH study in Uganda met initial eligibility criteria of a rural community, defined as one or more national geopolitical units, just above the village level (i.e. a parish) with a population of about 10,000 persons within the catchment area of a President's Emergency Plan for AIDS Relief (PEPFAR)-supported HIV clinic in southwestern Uganda or Eastern Uganda and matched pairs were selected based on region, population density, occupational mix, access to transport routes, and number of trading centres [21]. Among the approximately 10,000 persons residing in each community, approximately $50 \%$ are adults age $\geq 18$ years. Following a baseline census, each community held a community health campaign (CHC) offering multi-disease screening, treatment and linkage to care. Point-of-care screening for HIV, hypertension, and diabetes was offered to all adults (age $\geq 18$ years) [19] and persons screening positive for any condition were linked to care at a nearby health center. All HIV-positive persons were offered the first line regimen in Uganda at the time of efavirenz, tenofovir disoproxil fumurate, and emtricitabine [22].

\section{Hypertension definition}

We defined HTN based on World Health Organization (WHO) guidelines as a systolic $\mathrm{BP} \geq 140$ or diastolic $\mathrm{BP} \geq 90 \mathrm{mmHg}$ on any one of three measurements [23] or self-reported current use of anti-hypertensives. Stage 1 hypertension was defined as highest systolic $\mathrm{BP}>=$ $140 \mathrm{mmHg}$ and $<160 \mathrm{mmHg}$ OR highest diastolic BP $\geq$ $90 \mathrm{mmHg}$ and $<100 \mathrm{mmHg}$. Stage 2 hypertension was defined as highest systolic $\mathrm{BP} \geq 160 \mathrm{mmHG}$ or $\mathrm{DBP} \geq$ $100 \mathrm{mmHg}$. Hypertension control was defined as systolic $\mathrm{BP}<140$ AND diastolic $\mathrm{BP}<90 \mathrm{mmHg}$ on all three blood pressure measurements.

\section{Clinic procedures}

Participants who screened positive for hypertension at the $\mathrm{CHC}$ were referred to their local health facility for NCD management. An integrated chronic disease model of streamlined care designed to reduce patient level 
barriers and maximize health system efficiency [20] was implemented at all local clinics. HIV and NCD care were co-located and HIV care was part of a chronic disease care model that offered joint evaluation and management of hypertension, diabetes, and general medical conditions. HIV-infected patients received HIV and NCD-focused care simultaneously during their visit. HIV-uninfected persons received treatment for hypertension and/or diabetes.

At the clinic visit blood pressure was measured using electronic sphygmomanometers. Individuals with hypertension were managed using a clinical and medication management algorithm based on the Uganda Clinical Guidelines [24] [Additional files 1 and 2]. Patients with Stage 1 hypertension were initially managed with a 3 -month trial of lifestyle changes. If a patient's blood pressure remained elevated after that trial, then the patient was prescribed blood pressure lowering medication and scheduled to return in 4 weeks. On subsequent visits, individuals with uncontrolled blood pressure were scheduled to return to clinic 4 weeks later for repeat blood pressure check and medication titration if necessary. Per algorithm, those with controlled blood pressure were scheduled to follow-up in 3 months. However, in practice, patients with controlled blood pressure were often scheduled to return to clinic earlier (e.g. after 4-6 weeks rather than the 3 months indicated) due to drug stock outs. All patients with malignant hypertension (BP $>180 / 110 \mathrm{mmHg}$ ) were referred immediately to the clinical officer for urgent treatment at the health facility.

\section{Outcome}

The primary outcome of interest for this analysis was hypertension control at follow-up clinic visits. Blood pressure control at 2 consecutive visits separated by at least 1 month was evaluated as a secondary outcome.

\section{Analysis}

We described univariate distributions of demographic and clinical variables overall and separately among HIV-infected and uninfected individuals. Demographic characteristics of those who linked to care were compared with those who screened positive for HTN at $\mathrm{CHC}$ and did not link to care using logistic regression adjusting for clinic site. We classified a scheduled visit as 'more frequent than clinical indication' if blood pressure was controlled and the next clinic visit was scheduled within 84 days. Late visits were defined as visits made more than 14 days after the scheduled date.

We used a multilevel mixed-effects logistic regression [25] to evaluate our hypothesis that scheduled visits more frequent than clinical indication would be associated with worse blood pressure control at follow-up visits. We identified covariates a priori for inclusion in multivariate analysis based on known factor related to blood pressure control. In final multivariate analysis we adjusted for individual characteristics (age, sex, comorbid diabetes based on chart review, HIV-status at baseline), clinic, time-varying clinical characteristics (hypertension stage at previous visit, medications prescribed at previous visit), and calendar time (follow-up time in months). Clinic site was modeled as a fixed effect because we were interested in quantifying between-clinic heterogeneity and to control for the depends of all individuals within a clinic. Individuals were modeled as random effects to account for intra-individual correlation in the outcome. All individuals who had at least one follow-up visit were included in the analysis. All analyses were conducted with Stata version 14.2 (Statacorp LP, College Station, Texas).

\section{Ethics}

This study and all consent procedures were approved by ethical review boards of Makerere University School of Medicine (Kampala, Uganda) and the University of California, San Francisco (USA). All participants provided verbal informed consent at the $\mathrm{CHC}$ in their preferred language with fingerprint biometric confirmation of agreement. Verbal consent was provided in lieu of written consent as the $\mathrm{CHC}$ activities presented no more than minimal risk of harm to subjects and did not involve procedures for which written consent would otherwise be provided, and because of limited literacy in the study population.

\section{Results}

\section{Population screening and linkage to care}

Across ten communities, 34,704 residents aged $\geq 18$ years were evaluated at baseline, of whom 2071 (6\%) were HIV-infected [Fig. 1, Table 1]. Among HIV-infected adults, 199/2071 (10\%) screened positive for hypertension. Among HIV-uninfected individuals 4355/32,633 (13\%) screened positive.

Within one year, 45\% (2038/4554) of individuals who screened positive for hypertension linked to NCD care during the baseline year [Fig. 1]. Among those who linked, 69\% (1189/2038) were women, with a median age of 56 years (IQR 45-68 years) and median BMI of 22.4 (IQR 20.0-25.8). Participants who screened positive for hypertension and linked to care were more likely to be female ( $52 \%$ vs $43 \%, p<0.001$ ), older (mean age 55.5 vs 48.8 years, $p<0.001$ ), and have Stage 2 hypertension at screening $(p<0.001)$ than those who did not link to NCD care. At their first clinic visit, 294/2038 (15\%) of individuals were on blood pressure lowering medication, 714/2038 (35\%) had Stage 2 hypertension, and 123/2038 (6\%) were also being treated for diabetes. Among the 89 HIV-infected participants who linked to NCD care, 31 


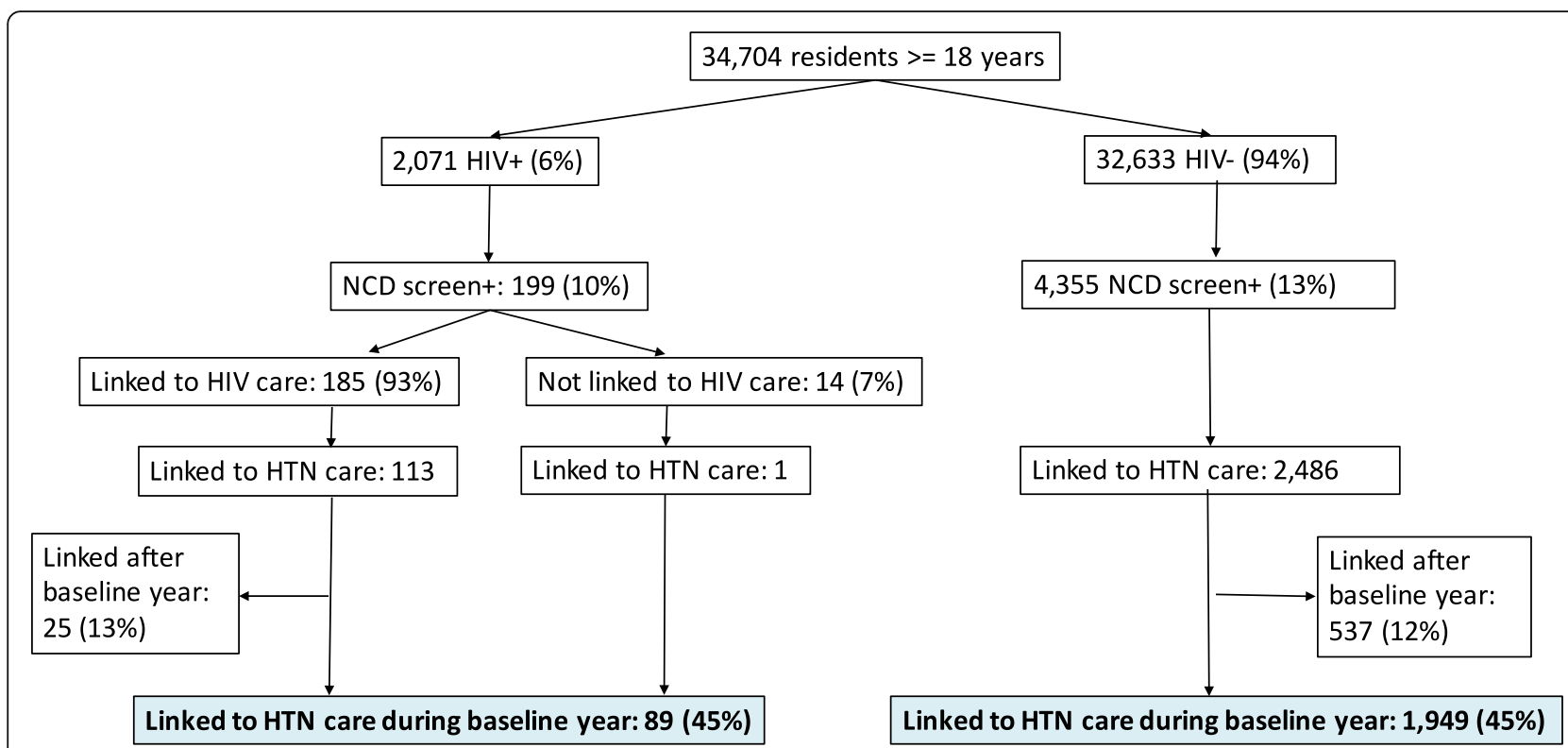

Fig. 1 Population screened for HIV and hypertension and linked to hypertension care within one year in the SEARCH Study

(36.9\%) had HIV RNA $<400$ copies/mL at baseline [Table 1].

\section{Hypertension care}

Overall, the 2038 patients who linked to HTN care made 16,253 total visits over 3 years of follow-up; of these, 1587 patients contributed 15,653 visits after the initial linkage visit [Table 2]. The median duration of between follow-up visits was 583 days (IQR 84-1122 days) among HIV-infected patients and 742 days (IQR 48-1198 days) among the HIV uninfected participants. Actual visits occurred $>14$ days after the scheduled date (late visits) at $18 \%(2975 / 2038)$ of visits. Among visits where hypertension was uncontrolled, 65\% (6229/ 8179) of subsequent follow-up visits were scheduled at $>30$ days (less frequently than guidelines). Among visits where hypertension was controlled, 43\% (3197/ 7474) of subsequent follow-up were scheduled at $<84$ days (more frequently than clinical guidelines) due to drug stock outs. Patients' blood pressure was controlled at $46 \%(44-48 \%)$ of follow-up visits.

Approximately two thirds of the patients (1333/2038) were treated with blood pressure lowering medicines and of these $65 \%(909 / 1333)$ were treated with 2 or more medications. Almost all (1290/1333, 96\%) of those treated with medications were prescribed bendroflumethiazide (a thiazide diuretic) and 902/1333 (68\%) were treated with nifedipine (a dihydropyridine calcium channel blocker). The remaining third who were never prescribed blood pressure lowering medication were

Table 1 Demographic characteristics of individuals who linked to hypertension care after population-based screening at their baseline clinic visitn $(N=2038)$

\begin{tabular}{llll}
\hline & $H I V+(n=89)$ & $H I V-(n=1949)$ & Overall (N=2038) \\
\hline Sex & & & $847(42 \%)$ \\
$\quad$ Male $[n(\%)]$ & $27(30 \%)$ & $820(42 \%)$ & $1189(58 \%)$ \\
$\quad$ Female $[n(\%)]$ & $60(70 \%)$ & $1129(58 \%)$ & $56(45,68)$ \\
Age $[$ Median (IQR)] & $46(40,54)$ & $56(45,69)$ & $22.4(20.0,25.8)^{\mathrm{a}}$ \\
BMI [Median (IQR)] & $22.2(20.4,25.0)$ & $22.4(20.0,25.9)$ & $294(15 \%)$ \\
On antihypertensive medication [n(\%)] & $10(11 \%)$ & $284(15 \%)$ & $778(38 \%)$ \\
Stage 1 Hypertension $[\mathrm{n}(\%)]$ & $32(36 \%)$ & $746(38 \%)$ & $714(35 \%)$ \\
Stage 2 Hypertension $[\mathrm{n}(\%)]$ & $32(36 \%)$ & $682(35 \%)$ & $123(6 \%)$ \\
Diabetes & $4(4 \%)$ & $119(6 \%)$ & $\mathrm{NA}$ \\
HIV RNA $<=500$ copies/mL $[\mathrm{n}(\%)]$ & $31(34.8 \%)$ & $\mathrm{NA}$ & \\
\hline
\end{tabular}

\footnotetext{
a missing data in $n=89(4 \%)$
} 
Table 2 Follow-up clinic visits among those who linked to hypertension care after population level screening $(N=2038)$

\begin{tabular}{|c|c|c|c|}
\hline & $\mathrm{HIV}+(n=89)$ & HIV- $(n=1949)$ & Overall $(N=2038)$ \\
\hline Total number of follow-up visits & 580 & 15,073 & 15,653 \\
\hline Median duration of follow-up (days) (IQR) & $583(84,1122)$ & $742(48,1198)$ & $738(50,1195)$ \\
\hline Interval in days between scheduled visits [Median (IQR)] & $59(29,84)$ & $56(29,84)$ & $56(29,84)$ \\
\hline Interval in days between actual visits [Median (IQR)] & $65(42,90)$ & $63(35,91)$ & $63(35,91)$ \\
\hline \multicolumn{4}{|l|}{ Interval between scheduled visits } \\
\hline More frequent than clinical indication & $141(24 \%)$ & $3056(20 \%)$ & $3197(20 \%)$ \\
\hline Less frequent than clinical indication & $216(37 \%)$ & $6013(39 \%)$ & $6229(39 \%)$ \\
\hline Late visits $^{\mathrm{a}}[\%$, median (IQR)] & $150(24 \%)$ & $2825(18 \%)$ & $2975(18 \%)$ \\
\hline Follow-up visits with controlled blood pressure & $301(48 \%)$ & $7173(46 \%)$ & $7474(46 \%)$ \\
\hline Follow-up visits with controlled blood pressure on 2 consecutive visits & $182(34 \%)$ & $4160(29 \%)$ & $4342(29 \%)$ \\
\hline Visits with no blood pressure measurement & $33(3.5 \%)$ & $609(3.5 \%)$ & $641(3.5 \%)$ \\
\hline
\end{tabular}

late visit defined as $>14$ days after scheduled visit

managed though counseling on lifestyles changes, including decreasing salt intake, exercise, and alcohol consumption [Table 3].

\section{Predictors of hypertension control}

After adjusting for age, sex, comorbid diabetes, hypertension stage at previous visit, medication prescribed at previous visit, HIV status, and clinic, scheduled visit interval outside of clinical indication was significantly associated with blood pressure control. Scheduled visit interval more frequent than clinical indication for patients with controlled HTN was associated with lower HTN control (aOR $=0.89 ; 95 \%$ CI 0.79-0.99). Men (aOR 0.88 ; $95 \%$ CI $0.78-0.99)$ and patients age 50 years and older (aOR 0.83; 95\% CI $0.73-0.95)$ were less likely to have controlled blood pressure at follow-up visits than women and patients less than 50 years old. Time in care (in months) was associated with higher odds of blood pressure control (aOR 1.03; 95\% CI 1.03-1.04). HIV-infected patients were more likely than uninfected patients to have controlled blood pressure at follow-up visits (aOR 1.28; 95\% CI 1.00-1.77) [Table 4]. When 2 consecutive clinic visits with controlled hypertension was the outcome age $>=50$ years $(\mathrm{aOR} 0.73 ; 95 \% \mathrm{CI}$ $0.58-0.93$ ) and scheduled visit interval more frequent than clinical indication for patients with controlled HTN (aOR 0.80; 95\% CI 0.52-0.99) were associated with lower odds of HTN control [Table 5].

\section{Discussion}

To work towards hypertension control in SSA we need to optimize health systems for chronic care delivery. In

Table 3 Hypertension treatment among those receiving care in clinic $(N=2038)$

\begin{tabular}{llll}
\hline & $H I V+(n=89)$ & $H I V-(n=1949)$ & Overall (N=2038) \\
\hline $\begin{array}{l}\text { Treatment } \\
\text { Blood pressure lowering medications [n(\%)] }\end{array}$ & $60(67 \%)$ & $1275(65 \%)$ & $1333(65 \%)$ \\
Lifestyle changes [n(\%)] & $29(33 \%)$ & $674(35 \%)$ & $703(35 \%)$ \\
Number of Blood Pressure Medications & & & $424(21 \%)$ \\
1 & $21(23 \%)$ & $404(21 \%)$ & $745(37 \%)$ \\
2 & $23(25 \%)$ & $723(37 \%)$ & $164(8 \%)$ \\
$>=3$ & $6(7 \%)$ & $158(8 \%)$ & $1290(96 \%)$ \\
Frequency of prescribed medications [n(\%)] & & $1245(98 \%)$ & $902(68 \%)$ \\
Bendroflumethiazide & $46(54 \%)$ & $875(67 \%)$ & $256(19 \%)$ \\
Nifedipine & $29(33 \%)$ & $246(19 \%)$ & $224(17 \%)$ \\
Atenolol & $10(13 \%)$ & $216(17 \%)$ & $39(3 \%)$ \\
Captopril & $8(9 \%)$ & $38(3 \%)$ & $26(2 \%)$ \\
Furosemide & $1(2 \%)$ & $26(2 \%)$ & $25(2 \%)$ \\
Propranolol & 0 & $24(2 \%)$ & $2 \%)$ \\
Amlodipine & $1(2 \%)$ & & 25 \\
\hline
\end{tabular}


Table 4 Predictors of hypertension control among patients who linked to hypertension care following population-level screening and had at least one subsequent follow-up visit $(n=1587)$

\begin{tabular}{|c|c|c|c|c|}
\hline & $\begin{array}{l}\text { Unadjusted OR } \\
\text { (95\% Cl) for HTN } \\
\text { control }\end{array}$ & $p$-value & $\begin{array}{l}\text { Adjusted OR } \\
(95 \% \text { Cl) for HTN } \\
\text { control }\end{array}$ & $p$ value \\
\hline Sex & & 0.08 & & 0.03 \\
\hline Female & 1.0 & & 1.0 & \\
\hline Male & $0.87(0.75,1.01)$ & & $0.88(0.78,0.99)$ & \\
\hline Age & & 0.02 & & 0.01 \\
\hline$<50$ years & 1.0 & & 1.0 & \\
\hline$>=50$ years & $0.82(0.69,0.97)$ & & $0.83(0.73,0.95)$ & \\
\hline Diabetes present & & 0.9 & & 0.8 \\
\hline No & 1.0 & & 1.0 & \\
\hline Yes & $1.02(0.80,1.31)$ & & $0.98(0.80,1.19)$ & \\
\hline Time since first clinic visit (months) & $1.03(1.03,1.03)$ & $<0.001$ & $1.02(1.01,1.02)$ & $<0.001$ \\
\hline \multicolumn{5}{|l|}{ Hypertension Stage at previous visit } \\
\hline 0 & 1.0 & $<0.001$ & 1.0 & $<0.001$ \\
\hline 1 & $0.51(0.46,0.57)$ & & $0.63(0.55,0.71)$ & \\
\hline 2 & $0.26(0.23,0.29)$ & & $0.33(0.28,0.38)$ & \\
\hline Anti-hypertensive Medication prescribed at previous visit & & 0.02 & & 0.15 \\
\hline Yes & $1.26(1.07,1.49)$ & & $1.09(0.94,1.26)$ & \\
\hline No & 1.0 & & 1.0 & \\
\hline HIV Status & & 0.04 & & 0.11 \\
\hline Known-infected & $1.35(1.02,1.78)$ & & $1.28(0.95,1.71)$ & \\
\hline Known-uninfected & 1.0 & & 1.0 & \\
\hline Scheduled visit interval & & 0.03 & & 0.05 \\
\hline Per HTN treatment guidelines* & 1.0 & & 1.0 & \\
\hline More frequently than guidelines* & $0.81(0.75,0.87)$ & & $0.89(0.79,0.99)$ & \\
\hline Clinic & & $<0.001$ & & $<0.001$ \\
\hline Bugamba & $0.65(0.50,0.85)$ & & $0.67(0.54,0.85)$ & \\
\hline Kameke & $4.37(3.19,6.00)$ & & $3.79(2.86,5.04)$ & \\
\hline Kamuge & $1.39(1.10,1.75)$ & & $1.64(1.34,2.00)$ & \\
\hline Kazo & $1.64(1.18,2.29)$ & & $1.60(1.20,2.11)$ & \\
\hline Merikit & $1.81(1.37,2.31)$ & & $1.74(1.38,2.19)$ & \\
\hline Mitooma & 1.0 & & 1.0 & \\
\hline Muyembe & $1.91(1.45,2.52)$ & & $1.89(1.50,2.37)$ & \\
\hline Nankoma & $1.91(1.39,2.64)$ & & $1.89(1.50,2.37)$ & \\
\hline Rubaare & $1.07(0.78,1.48)$ & & $1.10(0.85,1.44)$ & \\
\hline Ruhoko & $1.26(0.91,1.73)$ & & $1.16(0.91,1.49)$ & \\
\hline
\end{tabular}

*Guidelines are to schedule follow-up visit 4 weeks later for patients with uncontrolled hypertension (stage 1 or stage 2 ) and every 3 months for patients with controlled hypertension (stage 0 ) at previous visit. More frequently than guidelines is a scheduled follow-up visit $<84$ days when blood pressure is controlled (SBP $<140$ and $\mathrm{DBP}<90)$

this study of hypertension outcomes among patients referred to integrated chronic disease care after population-wide screening we found that blood pressure control increased more than threefold from $15 \%$ at baseline. Nevertheless, blood pressure was controlled in slightly less than half (46\%) of all follow-up visits. We identified a modifiable systems factor, more frequent clinic visits precipitated by drug stock outs, as one of the barriers to hypertension control.

Achieving hypertension control at a population level starts with screening and linkage to clinical care. After population-based screening, $45 \%$ of patients with 
Table 5 Predictors of hypertension control at two consecutive visits among patients who linked to hypertension care following population-level screening and had at least two subsequent follow-up visits ( $n=1327)$

\begin{tabular}{|c|c|c|c|c|}
\hline & $\begin{array}{l}\text { Unadjusted OR } \\
\text { (95\% Cl) for HTN } \\
\text { control }\end{array}$ & $p$-value & $\begin{array}{l}\text { Adjusted OR } \\
(95 \% \mathrm{Cl}) \text { for } \\
\text { HTN control }\end{array}$ & $p$ value \\
\hline Sex & & 0.08 & & 0.09 \\
\hline Female & 1.0 & & 1.0 & \\
\hline Male & $0.82(0.65,1.02)$ & & $0.83(0.68,1.03)$ & \\
\hline Age & & 0.008 & & 0.009 \\
\hline$<50$ years & 1.0 & & 1.0 & \\
\hline$>=50$ years & $0.72(0.56,0.92)$ & & $0.73(0.58,0.91)$ & \\
\hline Diabetes present & & 0.99 & & 0.99 \\
\hline No & 1.0 & & 1.0 & \\
\hline Yes & $0.99(0.71,1.39)$ & & $1.01(0.72,1.39)$ & \\
\hline Time since first clinic visit (months) & $1.03(1.03,1.04)$ & $<0.001$ & $1.03(1.02,1.04)$ & $<0.001$ \\
\hline Hypertension Stage at previous visit & & $<0.001$ & & $<0.001$ \\
\hline 0 & 1.0 & & 1.0 & \\
\hline 1 & $0.87(0.69,1.08)$ & & $0.89(0.78,0.99)$ & \\
\hline 2 & $0.42(0.07,2.52$ & & $0.79(0.67,0.91)$ & \\
\hline Anti-hypertensive Medication prescribed at previous visit & & 0.009 & & 0.28 \\
\hline Yes & $0.74(0.59,0.93)$ & 0.03 & $1.03(0.89,1.14)$ & 0.21 \\
\hline No & 1.0 & & 1.0 & \\
\hline HIV Status & & 0.06 & & 0.07 \\
\hline Known-infected & $1.81(0.97,3.41)$ & & $1.54(0.93,2.65)$ & \\
\hline Known-uninfected & 1.0 & & 1.0 & \\
\hline \multicolumn{5}{|l|}{ Scheduled visit interval } \\
\hline Per HTN treatment guidelines & 1.0 & $<0.001$ & 1.0 & 0.02 \\
\hline More frequently than guidelines & $0.68(0.37,0.98)$ & & $0.80(0.52,0.99)$ & \\
\hline \multicolumn{5}{|l|}{ Clinic } \\
\hline Bugamba & $0.36(0.24,0.53)$ & & $0.46(0.31,0.68)$ & \\
\hline Kameke & $6.98(4.62,10.54)$ & & $5.05(3.30,7.72)$ & \\
\hline Kamuge & $1.34(0.97,1.85)$ & & $1.21(0.88,1.68)$ & \\
\hline Kazo & $0.74(0.45,1.22)$ & & $0.77(0.46,1.31)$ & \\
\hline Merikit & $1.77(1.19,2.61)$ & & $1.10(0.74,1.61)$ & \\
\hline Mitooma & 1.0 & & 1.0 & \\
\hline Muyembe & $2.32(1.60,3.37)$ & & $1.24(0.85,1.81)$ & \\
\hline Nankoma & $2.76(1.80,4.22)$ & & $2.30(1.48,3.56)$ & \\
\hline Rubaare & $0.87(0.56,1.35)$ & & $0.80(0.50,1.28)$ & \\
\hline Ruhoko & $1.15(0.74,1.78)$ & & $0.45(0.29,0.69)$ & \\
\hline
\end{tabular}

prevalent hypertension were linked to NCD care. This number may underestimate true linkage, however, as individuals who were normotensive on presentation to clinic and not enrolled in NCD care were not counted, however they still fall short of ideal. Linkage to NCD care following screening remains a challenge across the region - a recent meta-analysis on hypertension in SSA estimated only $14-22 \%$ patients were in care following hypertension diagnosis [5]. Our population-based, multi-disease approach may have increased linkage by increasing health-seeking behavior in the communities; however, additional efforts targeted towards engagement in NCD care are needed.

Our population who sought care were approximately two thirds female, while population-based screening demonstrated higher prevalence among men [26]. Our 
clinic population that is enriched for women is similar to other reported clinic populations [7] likely reflects the health care seeking behavior of women in a health care system created primarily for women and children. Only $15 \%$ were on blood pressure lowering medications at baseline, reflecting the large burden of undiagnosed disease in this part of the world. Over $1 / 3$ had stage 2 hypertension at the time of screening suggesting this undiagnosed burden is severe.

We found that hypertension control was achieved at $46 \%$ of follow-up visits. This is similar to findings of a multisite population population-based screening across 6 sites in South Africa, Kenya, Ghana, Burkina Faso, Sierra Leone where HTN control in $47 \%$ of those in treatment [8] and slightly higher than $37 \%$ hypertension control among those on blood pressure lowering medication in a population based study in Malawi [6]. However, we measure hypertension control over time rather than a single point estimate, which provides a more complete picture of hypertension control in the clinic community.

Similar to findings that improved HIV outcomes are associated with extended intervals between scheduled clinic visits [17, 18], we found that patients whose scheduled visit intervals were more frequent than clinical guidelines had worse BP control. Medication stock levels contributed to more frequent scheduled visits (i.e. $<12$ weeks despite hypertension control) at $20 \%$ of visits. This finding provides critical information for targeting reduced patient visits per clinical guidelines for efficient chronic care for stable controlled patients and ensuring the clinic infrastructure, including drug supply, can support less frequent visits. More reliable drug supply chains for NCDs will be crucial to this effort [27].

Patients with dual diagnoses of HIV and hypertension were more likely to achieve normal blood pressure over time than those patients receiving care for hypertension only. Hypertension care was integrated into HIV clinic visits preventing redundant visits and HIV-infected patients also received extensive counseling about daily medication adherence and retention support which may have led to increased adherence among HIV-infected patients. These tools can be adapted to support engagement in care for other chronic disease to improve outcomes.

Other integration initiatives can inform the successful integration of HIV and hypertension care. Integrated TB and HIV care leads to decreased both HIV and TB-associated morbidity and mortality [28]. Co-location of services is associated with fewer delays in starting ART and greater uptake of ART among HIV/TB co-infected patients [29-31] versus referral to a separate facility for TB or HIV care. Similarly, integration of family planning and HIV counseling and testing increases uptake of both among post-partum women when compared to stand-alone service delivery [32]. We provided integrated HIV and hypertension care under the same roof enabling "one-stop" shopping for patients. As hypertension and chronic care for other NCDs is integrated with HIV chronic care across SSA, co-located services, a well-trained workforce, and clinic infrastructure will likely be crucial to successful treatment of both.

Our data only captures individuals who are in care for hypertension treatment; outcomes following transfer or loss to care were not assessed. Nonetheless, understanding blood pressure control among those individuals receiving treatment is important to improving outcomes within the health care system. More detailed analysis of the effect of class of antihypertensive treatment would provide additional insight into mechanisms of blood pressure control, however the focus of this current analysis is on individual clinical factors and health systems factors that contribute to hypertension control. Additionally, blood pressure measured at clinic represents a single point in time and we thus have an incomplete picture of overall hypertension control in this population. Clinic-based blood pressure measurements potentially misclassify individuals with white coat hypertension (where an individual presents as hypertensive in clinic but is normotensive out of clinic) or masked hypertension (where an individual presents as normotensive in clinic but has elevated blood pressure on ambulatory or home BP monitoring) and the prevalence in SSA is estimated to be 15 and $11 \%$ respectively [33]. However, these misclassifications would likely bias our results towards the null. Finally, adherence to blood pressure lowering medications was not evaluated in this analysis, however adherence to medication is likely reflected in the blood pressure measurements performed in clinic. Future work will probe adherence and challenges to adherence among those with poor hypertension control.

\section{Conclusion}

Our study registered successes in population level screening for HIV and hypertension, in linkage to integrated chronic disease care and hypertension control for both HIV positive and HIV negative patients with hypertension. Our study contributes evidence to realize effective responses for HIV care and emerging NCDs, including hypertension, in SSA. However, there is need to continue to optimize the integrated care model to achieve ideal patient outcomes.

\section{Additional files}

Additional file 1: Hypertension Management Algorithm (PDF 70 kb) Additional file 2: Hypertension Drug Use Algorithm (PDF 172 kb)

\section{Abbreviations}

ART: Antiretroviral therapy; BP: Blood Pressure; CHC: Community health campaign; DBP: Diastolic blood pressure; HIV: Human immunodeficiency 
virus; HTN: Hypertension; NCD: Non-communicable disease; PLHIV: People living with HIV; SBP: Systolic blood pressure; SSA: Sub-Saharan Africa; TB: Tuberculosis; WHO: World Health Organization

\section{Acknowledgements}

Not applicable

\section{Funding}

Research reported in this manuscript was supported by the Division of AIDS, NIAID of the National Institutes of Health under award numbers U01A1099959 and UM1AI068636. The study funders did not play any role in the design, collection, analysis, interpretation of the data.

\section{Availability of data and materials}

The datasets generated and/or analyzed during the current review are not publicly available due to ongoing analysis as part of the RCT evaluation, but are available from the corresponding author on reasonable request.

\section{Authors' contributions}

DK, DVH, and LBB conceptualized the analysis and drafted the manuscript with input from all co-authors. LBB performed all data analysis. MA, AO, JK, $\mathrm{DB}, \mathrm{FM}$, contributed to data collection and interpretation. GC, TC, VJ, LB, MP, $E C, M K$, and DVH. designed the study. All co-authors read and approved the manuscript. All authors read and approved the final manuscript.

\section{Ethics approval and consent to participate}

This study and all consent procedures were approved by ethical review boards of Makerere University School of Medicine (Kampala, Uganda) and the University of California, San Francisco (USA). All participants provided verbal informed consent at the CHC in their preferred language with fingerprint biometric confirmation of agreement. Verbal consent was provided in lieu of written consent as the $\mathrm{CHC}$ activities presented no more than minimal risk of harm to subjects and did not involve procedures for which written consent would otherwise be provided, and because of limited literacy in the study population.

\section{Consent for publication}

Not applicable

\section{Competing interests}

V.J. has received grant support from Gilead Sciences. D.V.H. has received non-financial support from Gilead Sciences. All authors have no other competing of interest to declare.

\section{Publisher's Note}

Springer Nature remains neutral with regard to jurisdictional claims in published maps and institutional affiliations.

\section{Author details}

${ }^{1}$ Infectious Diseases Research Collaboration, Kampala, Uganda. ${ }^{2}$ University of California San Francisco, San Francisco, CA, USA. ${ }^{3}$ University of Massachusetts, Amherst, MA, USA. ${ }^{4}$ Makerere University College of Health Sciences, Kampala, Uganda. ${ }^{5}$ University of California, Berkeley, CA, USA.

Received: 15 January 2019 Accepted: 15 April 2019

Published online: 06 May 2019

\section{References}

1. Lim SS, Vos T, Flaxman AD, Danaei G, Shibuya K, Adair-Rohani H, et al. A comparative risk assessment of burden of disease and injury attributable to 67 risk factors and risk factor clusters in 21 regions, 1990-2010: a systematic analysis for the global burden of disease study 2010. Lancet. 2012;380(9859):2224-60

2. Daniels M, Donilon T, Bollyky T. The emerging global health crisis: noncommunicable diseases in low-and middle-income countries; 2014.

3. Patel P, Rose CE, Collins PY, Nuche-Berenguer B, Sahasrabuddhe W, Peprah $E$, et al. Noncommunicable diseases among HIV-infected persons in lowincome and middle-income countries: a systematic review and metaanalysis. AIDS (London, England). 2018;32:S5-S20.

4. Organization WH. A global brief on hypertension: silent killer, global public health crisis. Geneva, Switzerland: World Health Organization; 2013.
5. Ataklte F, Erqou S, Kaptoge S, Taye B, Echouffo-Tcheugui JB, Kengne AP. Burden of undiagnosed hypertension in sub-saharan Africa: a systematic review and meta-analysis. Hypertension. 2015;65(2):291-8.

6. Price AJ, Crampin AC, Amberbir A, Kayuni-Chihana N, Musicha C, Tafatatha $T$, et al. Prevalence of obesity, hypertension, and diabetes, and cascade of care in sub-Saharan Africa: a cross-sectional, populationbased study in rural and urban Malawi. Lancet Diabetes Endocrinol. 2018;6(3):208-222. Epub 2018/01/27. doi: https://doi.org/10.1016/s22138587(17)30432-1. PubMed PMID. 29371076: PubMed Central PMCID: PMCPMC5835666.

7. Antignac M, Diop IB, Macquart de Terline D, Kramoh KE, Balde DM, Dzudie A, et al. Socioeconomic Status and Hypertension Control in Sub-Saharan Africa: The Multination EIGHT Study (Evaluation of Hypertension in SubSaharan Africa). Hypertension (Dallas, Tex: 1979). 2018;71(4):577-584. Epub 2018/01/31. doi: https://doi.org/10.1161/hypertensionaha.117.10512. PubMed PMID: 29378852.

8. Gómez-Olivé FX, Ali SA, Made F, Kyobutungi C, Nonterah E, Micklesfield L, et al. Regional and sex differences in the prevalence and awareness of hypertension: an H3Africa AWl-gen study across 6 sites in sub-Saharan Africa. Glob Heart. 2017;12(2):81-90.

9. HIV/AIDS JUNPo. Global Report: UNAIDS report on the global AIDS epidemic 2013. Geneva: UNAIDS; 2013. According to the UNAIDS'estimate the number of new infections in the region increased from. 2017;21:22,000-47,.

10. Wandeler G, Johnson LF, Egger M. Trends in life expectancy of HIV-positive adults on antiretroviral therapy across the globe: comparisons with general population. Current opinion in HIV and AIDS. 2016;11(5):492-500. Epub 2016/06/03. doi: https://doi.org/10.1097/coh.0000000000000298. PubMed PMID: 27254748; PubMed Central PMCID: PMCPMC5055447.

11. Survival of HIV-positive patients starting antiretroviral therapy between 1996 and 2013: a collaborative analysis of cohort studies. Lancet HIV. 2017:4(8): e349-ee56. Epub 2017/05/16. doi: https://doi.org/10.1016/s23523018(17)30066-8. PubMed PMID: 28501495; PubMed Central PMCID: PMCPMC5555438.

12. Deeks SG, Phillips AN. HIV infection, antiretroviral treatment, ageing, and non-AIDS related morbidity. Bmj. 2009;338:a3172.

13. Moore RD, Gebo KA, Lucas GM, Keruly JC. Rate of comorbidities not related to HIV infection or AIDS among HIV-infected patients, by CD4 cell count and HAART use status. Clin Infect Dis. 2008;47(8):1102-4.

14. Mwagomba BLM, Ameh S, Bongomin P, Juma PA, MacKenzie RK, Kyobutungi $C$, et al. Opportunities and challenges for evidence-informed HIV-noncommunicable disease integrated care policies and programs: lessons from Malawi, South Africa, Swaziland and Kenya. AIDS (London, England). 2018;32:S21-32.

15. Geng EH, Odeny TA, Lyamuya R, Nakiwogga-Muwanga A, Diero L, Bwana M, et al. Retention in care and patient-reported reasons for undocumented transfer or stopping care among HIV-infected patients on antiretroviral therapy in eastern Africa: application of a sampling-based approach. Clin Infect Dis. 2015. Epub 2015/12/19. doi: https://doi.org/10.1093/cid/civ1004. PubMed PMID: 26679625.

16. Vedanthan R, Kamano JH, Bloomfield GS, Manji I, Pastakia S, Kimaiyo SN. Engaging the Entire Care Cascade in Western Kenya: A Model to Achieve the Cardiovascular Disease Secondary Prevention Roadmap Goals. Global Heart. 2015;10(4):313-317. Epub 2015/12/26. doi: https:// doi.org/10.1016/j.gheart.2015.09.003. PubMed PMID: 26704963; PubMed Central PMCID: PMCPMC4691279.

17. Mody A, Roy M, Sikombe K, Savory T, Holmes C, Bolton-Moore C, et al. Improved Retention With 6-Month Clinic Return Intervals for Stable Human Immunodeficiency Virus-Infected Patients in Zambia. Clin Infect Dis. 2018; 66(2):237-243. Epub 2017/10/12. doi: https://doi.org/10.1093/cid/cix756. PubMed PMID: 29020295; PubMed Central PMCID: PMCPMC5850531.

18. Mutasa-Apollo T, Ford N, Wiens M, Socias ME, Negussie E, Wu P, et al. Effect of frequency of clinic visits and medication pick-up on antiretroviral treatment outcomes: a systematic literature review and meta-analysis. J Int AIDS Soc. 2017;20:21647.

19. Chamie G, Clark TD, Kabami J, Kadede K, Ssemmondo E, Steinfeld R, et al. A hybrid mobile approach for population-wide HIV testing in rural East Africa: an observational study. Lancet HIV. 2016;3(3):e111-e9.

20. Kwarisiima D, Kamya MR, Owaraganise A, Mwangwa F, Byonanebye DM, Ayieko J, et al. High rates of viral suppression in adults and children with high CD4+ counts using a streamlined ART delivery model in the SEARCH trial in rural Uganda and Kenya. J Int AIDS Soc. 2017;20(Suppl 4):21673. 
Epub 2017/08/05. doi: https://doi.org/10.7448/ias.20.5.21673. PubMed PMID: 28770596; PubMed Central PMCID: PMCPMC5577724.

21. Balzer LB, Petersen ML, van der Laan MJ, Consortium S. Adaptive pairmatching in randomized trials with unbiased and efficient effect estimation. Stat Med 2015;34(6):999-1011. Epub 2014/11/25. doi: https://doi.org/10. 1002/sim.6380. PubMed PMID: 25421503.

22. Petersen M, Balzer L, Kwarsiima D, Sang N, Chamie G, Ayieko J, et al. Association of implementation of a universal testing and treatment intervention with HIV diagnosis, receipt of antiretroviral therapy, and viral suppression in East Africa. Jama. 2017;317(21):2196-206.

23. WHO. 2003 World Health Organization (WHO)/International Society of Hypertension (ISH) statement on management of hypertension. J Hypertens. 2003;21:1983-1992.

24. Uganda Clinical Guidelines: National Guidelines for Management of Common Conditions. 2012

25. Laird NM, Ware JH. Random-effects models for longitudinal data. Biometrics. 1982;38(4):963-974. Epub 1982/12/01. PubMed PMID: 7168798.

26. Kwarisiima D, Balzer L, Heller D, Kotwani P, Chamie G, Clark T, et al. Population-based assessment of hypertension epidemiology and risk factors among HIV-positive and general populations in rural Uganda. PLoS One. 2016;11(5):e0156309.

27. Pastakia SD, Tran DN, Manji I, Wells C, Kinderknecht K, Ferris R. Building reliable supply chains for noncommunicable disease commodities: lessons learned from HIV and evidence needs. AIDS (London, England). 2018;32: S55-61.

28. Uyei J, Coetzee D, Macinko J, Weinberg SL, Guttmacher S. The influence of integrated tuberculosis and human immunodeficiency virus service delivery on patient outcomes. Int J Tuberc Lung Dis 2014;18(3):315-321. Epub 2014/ 03/29. doi: https://doi.org/10.5588/ijtld.13.0184. PubMed PMID: 24670569

29. Chehab JC, Vilakazi-Nhlapo AK, Vranken P, Peters A, Klausner JD. Current integration of tuberculosis (TB) and HIV services in South Africa, 2011. PloS One. 2013;8(3):e57791. Epub 2013/03/08. doi: https://doi.org/10.1371/journal. pone.0057791. PubMed PMID: 23469242; PubMed Central PMCID: PMCPMC3587619.

30. Lawn SD, Campbell L, Kaplan R, Boulle A, Cornell M, Kerschberger B, et al. Time to initiation of antiretroviral therapy among patients with HIVassociated tuberculosis in Cape Town, South Africa. J Acquir Immune Defic Syndr (1999). 2011;57(2):136-140. Epub 2011/03/26. doi: https://doi.org/10. 1097/QAl.0b013e3182199ee9. PubMed PMID: 21436714; PubMed Central PMCID: PMCPMC3717455.

31. Owiti P, Zachariah R, Bissell K, Kumar AM, Diero L, Carter EJ, et al. Integrating tuberculosis and HIV services in rural Kenya: uptake and outcomes. Public Health Action. 2015;5(1):36-44. Epub 2015/09/25. doi: https://doi.org/10. 5588/pha.14.0092. PubMed PMID: 26400600; PubMed Central PMCID: PMCPMC4525370.

32. Kimani J, Warren CE, Abuya T, Ndwiga C, Mayhew S, Vassall A, et al. Use of HIV counseling and testing and family planning services among postpartum women in Kenya: a multicentre, non-randomised trial. BMC Women's Health. 2015;15:104. Epub 2015/11/14. doi: https://doi.org/10.1186/s12905015-0262-6. PubMed PMID: 26563220; PubMed Central PMCID: PMCPMC4643518

33. Noubiap JJ, Nansseu JR, Nkeck JR, Nyaga UF, Bigna JJ. Prevalence of white coat and masked hypertension in Africa: A systematic review and metaanalysis. J Clin Hypertens (Greenwich, Conn). 2018. Epub 2018/07/10. doi: https://doi.org/10.1111/jch.13321. PubMed PMID: 29984891.

Ready to submit your research? Choose BMC and benefit from:

- fast, convenient online submission

- thorough peer review by experienced researchers in your field

- rapid publication on acceptance

- support for research data, including large and complex data types

- gold Open Access which fosters wider collaboration and increased citations

- maximum visibility for your research: over $100 \mathrm{M}$ website views per year

At BMC, research is always in progress.

Learn more biomedcentral.com/submissions 